\title{
Inclusão social e a política nacional de resíduos sólidos
}

\author{
Social inclusion and the national policy solid waste
}

\author{
Josyane Mansano ${ }^{1}$ \\ Alessandra Celestino Oliveira ${ }^{2}$
}

\begin{abstract}
Resumo
O objetivo deste estudo é demonstrar que a partir da inclusão social é possível efetividade no desenvolvimento sustentável. A Lei no 12.305, de 2 de agosto de 2010, intitulada Política Nacional de Resíduos Sólidos (PNRS), toma como um de seus princípios essa inclusão. A nova legislação trata, entre outras questões, o tratamento do resíduo sólido, bem como meios de sua destinação, também da responsabilidade compartilhada com a participação de todos, setor privado, setor público e coletividade. Com essa nova política, os resíduos que hoje são depositados indiscriminadamente na natureza, devem ser reciclados e colocados como matéria-prima novamente no mercado, e isso a partir da coleta seletiva realizada pelos catadores, com a participação inicial da comunidade. $O$ intuito por fim, é dar efetividade à nova Lei, para demonstrar a importância dos catadores, de suas famílias, e das cooperativas no processo de reciclagem.
\end{abstract}

Palavras-chave: Inclusão social. Coleta. Resíduos Sólidos. Responsabilidade Compartilhada.

\begin{abstract}
The objective of this study is to demonstrate that from social inclusion is possible effectiveness in sustainable development. Law No. 12,305 of 2 August 2010, entitled national policy of solid waste (PNRS), takes as one of its principles this inclusion. The new legislation, among other issues, the treatment of solid waste, as well as the means of their destination, also shared responsibility with the participation of all, the private sector, public sector and collectivity. With this new policy, waste that today are deposited indiscriminately in nature, should be recycled and posed as a raw material in the market again, and this from selective collection held by collectors, with initial participation of the community. The aim is to give the new law, effectiveness to demonstrate the importance of scavengers, their families, and cooperatives in the recycling process.
\end{abstract}

Keyword: Social inclusion. Collection. Solid Waste. Shared Responsibility.

1 Mestre em Direito pela Universidade de Marília - SP, Especialista em Direito Civil e Processo Civil, Professora de Direito na Univale - Ivaiporã(Pr) e FINAN - Nova Andradina - Ms., Advogada em Maringá.

2 Mestranda em Direito (UNIMAR-SP). 


\section{Introdução}

Com o advento da Política Nacional de Resíduos Sólidos, em agosto de 2010, muito se espera para a solução da problemática questão do resíduo. A nova política veio com grandes avanços, entre eles a responsabilidade e gestão compartilhada entre fabricantes, importadores, distribuidores, comerciantes, poder público e consumidores. Mas seu papel fundamental visa trazer a inclusão social dos catadores, e cooperativas de catadores. Essa inclusão tem o condão de facilitar a emancipação econômica dos catadores de materiais recicláveis e reutilizáveis, eliminando assim o volume dos lixões, os quais são o grande problema das grandes cidades.

A participação ativa do poder público, dando base operacional para as cooperativas de catadores tem o objetivo de fazer com que essa problemática tenha uma solução além de efetiva, também, ambientalmente correta.

No entanto, óbvio é que não adianta operacionalizar as cooperativas de catadores, se nas casas, empresas e até escolas não tiver uma conduta sustentável, ou seja, essa conscientização deve partir de toda a coletividade.

Somente através desse processo de conhecimento e, sobretudo, de educação social sobre o que significa ser ambientalmente sustentável é que a lei de resíduos sólidos terá a efetividade que se pretende, não sendo mais uma "letra morta", como tantas outras existentes.

É com a participação consciente dos fabricantes, importadores, distribuidores, comerciantes, e principalmente do consumidor, que esse ciclo será fechado.

Sendo justamente nesse ponto que entra em ação a logística reversa no ciclo do resíduo, que tem o condão de fazer com que a matéria prima que entra em um fábrica ao se transformar em produto final, destinado a um consumidor, e depois do uso ser descartado, tenha o processo inverso de reciclagem, assim, há aproveitamento do resíduo, em relação às sobras, e depois do consumo.

Desta forma, tem-se que trabalhar com essas externalidades que agridem de forma desumana o meio ambiente faz com que se possa respirar um ar até mais limpo, isso, porque a maioria dos recursos naturais é esgotável, sendo assim, se não forem reciclados um dia deixarão de existir, ou terão que ser substituídos, tornando o ciclo produtivo mais 18

ReVIStA de Direito Público, Londrina, v. 7, N. 2, P. 17-40, MAIO/AGo. 2012. 
oneroso. Por isso, por que não investir em reciclar tais resíduos? Por que não investir em educação ambiental? Por que não materializar a proposta da política de resíduos instituindo, apoiando e formalizando tais cooperativas? Até porque, a inclusão social de trabalhadores humildes que, durante anos, foram esquecidos pelo poder público, veem agora uma chance para se socializarem, trabalhando com aquilo que ninguém quer mais, ou seja, o lixo.

Operacionalizar esse sistema de reciclagem é antes de tudo preservar o meio ambiente, possibilitando um futuro sustentável, para as presentes e futuras gerações, como prevê o art. 225 da Constituição Federal.

Assim, o que se pretende é abrir os olhos de todos, poder público, empresários e toda a sociedade para a questão dos resíduos sólidos, demonstrando que há sim solução economicamente viável para manter o equilíbrio desta sociedade de risco que estamos vivendo, dando condições para essa operacionalização a partir da inclusão social dos catadores.

A partir de projetos simples como a coleta seletiva, por exemplo, é que haverá perspectiva para planejar um futuro ambientalmente sustentável, dando condições sociais de organização e desenvolvimento de modo a incentivar e viabilizar a gestão das cooperativas de catadores.

O objetivo de organizar esse ciclo está principalmente em melhorar a qualidade de vida dessa população, dando solução economicamente viável e ao mesmo tempo sustentável ao lixo.

\section{Resíduos sólidos}

Para iniciar o presente estudo, mister primeiramente esclarecer o que vem a ser o produto com o qual os catadores e as cooperativas irão lidar no dia-a-dia, ou seja, o resíduo.

Primeiramente tem-se por resíduo é tudo aquilo que é passivo, geralmente fruto do consumo, da fabricação e do rejeito.

No Brasil, a Associação Brasileira de Normas Técnicas (ABNT) conceitua e estabelece os padrões e normas para classificação e armazenamento dos resíduos sólidos por meio da NBR 10004:2004. 
De acordo com essa Norma, os resíduos sólidos são definidos como (ABNT, 2004, p.5):

\begin{abstract}
Resíduos no estado sólido e semi-sólido, que resultam de atividades da comunidade de origem: industrial, doméstica, hospitalar, comercial, agrícola, de serviços e de varrição. Ficam incluídos, nesta definição os lodos provenientes de sistemas de tratamento de água, aqueles gerados em equipamentos e instalações de controle de poluição, bem como determinados líquidos cujas particularidades tornem inviável o seu lançamento na rede pública de esgotos ou corpos d'água, ou exijam para isso soluções técnica e economicamente inviáveis em face à melhor tecnologia disponível.
\end{abstract}

Segundo Machado (2010, p. 578), exclui-se do conceito de resíduo sólido: "Os dissolvidos nos esgotos domésticos ou outros significativos poluentes existentes nos recursos hídricos, tais como a lama, resíduos sólidos dissolvidos ou suspensos na água, encontrados nos efluentes industriais, e materiais dissolvidos nas correntes de irrigação ou outros poluentes comunas da água.

Quanto à classificação dos resíduos sólidos, a NBR 10004:2004 cria duas classes, conforme os riscos potenciais ao meio ambiente (ABNT, 2004):

a) Resíduos Classe I - Perigosos: são aqueles que representam periculosidade ou uma das seguintes características: inflamabilidade, corrosividade, reatividade, toxicidade e patogenicidade, e apresentem significativo risco à saúde pública ou ao meio ambiente. Exs: óleos lubrificantes usados, resíduos de laboratórios, borras de tintas e de solventes, lodos de estações de tratamento de águas residuais, etc.;

b) Resíduos Classe II - Não Perigosos, apresentam duas subclasses:

- Resíduos Classe II A - Não inertes: não se enquadram como Resíduos Classe I ou Classe II-B. Podem ter propriedades como biodegradabilidade, combustibilidade ou solubilidade em água; e

- Resíduos Classe I/ B - Inertes: quando submetidos a um contato dinâmico e estático com a água destilada ou desionizada, à temperatura ambiente, não apresentando constituintes solubilizados a concentrações superiores aos padrões de potabilidade de água vigentes, excetuando-se os padrões de aspecto, cor, turbidez, dureza e sabor. Ex: rochas, tijolos, vidros, borrachas e certos plásticos. 
No que se refere ao armazenamento dos resíduos sólidos, a NBR 12235:1992 determina que (ABNT, 1992):

a) Resíduos Classe I - Perigosos: o armazenamento desses resíduos deve ser feito sem alterar a quantidade e a qualidade dos resíduos. O local deve ser adequado, com isolamento, segurança e inspeção semanais para que não haja perigo de contaminação ambiental e/ou riscos a saúde pública. Deve ficar longe de mananciais, redes viárias, núcleos habitacionais e logradouros públicos, conforme estabelecidas em legislações específicas;

b) Resíduos Classe II - Não Perigosos: as condições de armazenamento são menos severas, mas exigem cuidados especiais, para a escolha do local, o acondicionamento dos resíduos e as operações no local de armazenagem.

Embora as normas de armazenamento sejam claras, na prática a destinação dos resíduos sólidos, na sua grande maioria, não obedece esses padrões, uma vez que ainda são depositados em lixões ou em qualquer terreno a céu aberto. Para Leite e Beltrão (2009, p. 171), essa destinação não passa de "descargas livres dos resíduos sólidos no ambiente, sem tratamento algum, nem tampouco estudos ambientais e monitoramento".

Este tipo de destino é totalmente inviável também no caso de resíduos eletrônicos, pilhas, baterias, agrotóxicos, óleos lubrificantes, entre outros, por causa da quantidade de metais pesados existentes em sua composição, que podem causar sérios danos ao meio ambiente e a saúde da população.

Assim, o que se vê muitas vezes são legislações sem efetividade séria, fazendo assim com que muitas leis no assunto, virem mais uma "letra morta".

Desse levantamento, segundo Milaré (2005, p. 185), conclui-se que:

Não basta, entretanto, apenas legislar. É fundamental que todas as pessoas e autoridades responsáveis se lancem ao trabalho de tirar essas regras do limbo da teoria para a existência efetiva da vida real; na verdade, o maior dos problemas ambientais brasileiros é o desrespeito generalizado, impunido ou punível, à legislação vigente. É preciso, numa palavra, ultrapassar a ineficaz retórica ecológica - tão inócua quanto aborrecida - e chegar às ações concretas em favor do ambiente e da vida.

É nesse campo que a Política Nacional de Resíduos Sólidos, tende a avançar, além de unificar as legislações municipais e estaduais já existentes. 


\section{A Política Nacional de Resíduos Sólidos - apontamentos sobre a inclusão social}

Para tratar da coleta, tratamento e disposição de resíduos sólidos, o Brasil, aprovou a Lei no 12.305, de 2 de agosto de 2010, intitulada Política Nacional de Resíduos Sólidos (PNRS), com o objetivo de tutelar o meio ambiente por meio de Políticas Públicas.

A nova legislação trata, entre outras questões, da responsabilidade compartilhada, onde determina o dever de responsabilização com a participação de todos. Essa política visa incentivar a chamada logística reversa de resíduos que hoje são depositados indiscriminadamente na natureza.

A partir do Capítulo III, a Lei aborda a responsabilidade dos geradores de resíduos sólidos e do Poder Público, atribuindo a responsabilidade compartilhada destes, bem como de toda a coletividade. Aborda ainda a obrigação da logística reversa para fabricantes, importadores, distribuidores e comerciantes de determinados resíduos e uma forma de cooperação entre Poder Público e comunidade, incentivando a implementação e efetivação das cooperativas de catadores e da coleta seletiva. Enfim, tudo para dar destinação final ambientalmente adequada aos resíduos sólidos e rejeitos.

Discute-se como proteger o meio ambiente dos resíduos gerados coresponsabilizando o Poder Público, o setor empresarial e toda a coletividade, entendendo esse meio como o "conjunto de condições naturais em determinada região, ou, globalmente, em todo o planeta, e da influencia delas decorrentes que, atuando sobre os organismos vivos e os seres humanos, condicionam sua preservação, saúde e bem estar" (DE PLÁCIDO; SILVA, 2007, p. 1056).

A nova legislação traz em seu bojo algumas diretrizes a serem seguidas para a implementação das coletas, bem como das cooperativas de catadores, tema deste estudo.

Destaca-se, entre outros os artigos $15^{3}, \mathrm{~V}, 17^{4}, \mathrm{~V}, 18^{5}$, que trata do plano nacional, estadual e municipal de gestão integrada de resíduos sólidos, que traz como meta a inclusão

3 Art. 15. A União elaborará, sob a coordenação do Ministério do Meio Ambiente, o Plano Nacional de Resíduos Sólidos, com vigência por prazo indeterminado e horizonte de 20 (vinte) anos, a ser atualizado a cada 4 (quatro) anos, tendo como conteúdo mínimo: [...]

V - metas para a eliminação e recuperação de lixões, associadas à inclusão social e à emancipação econômica de catadores de materiais reutilizáveis e recicláveis;

4 Art. 17. O plano estadual de resíduos sólidos será elaborado para vigência por prazo indeterminado, abrangendo todo o território do Estado, com horizonte de atuação de 20 (vinte) anos e revisões a cada 4 (quatro) anos, e tendo como conteúdo mínimo: [..] 
social e emancipação econômica de catadores, dessa forma fazendo com que seja economicamente viável trabalhar com o resíduo.

Assim, espera-se que nas três esferas de governo, haja uma cooperação mútua para com a problemática da destinação do resíduo, fazendo com que isso gere primeiramente um futuro sustentável para presentes e futuras gerações, bem como renda para aqueles que deste ciclo de reciclagem vierem a participar.

É nesse intuito que o Art. $19, \mathrm{XI}$, da lei elenca que essa gestão integrada deve promover programas e ações voltados à participação destes interessados em participar do processo, como se vê a seguir:

Art. 19. O plano municipal de gestão integrada de resíduos sólidos tem o seguinte conteúdo mínimo: [...]

XI - programas e ações para a participação dos grupos interessados, em especial das cooperativas ou outras formas de associação de catadores de materiais reutilizáveis e recicláveis formadas por pessoas físicas de baixa renda, se houver;

É nesse ínterim, trazendo efetividade para os artigos de Lei, é que se pretende conscientizar a sociedade para com o destino do lixo, bem como as benesses de se reciclar tudo o que um dia foi usado, e que quando descartado acabaria em um aterro sanitário ou mesmo em um lixão a céu aberto, ferindo de morte o meio ambiente.

V - metas para a eliminação e recuperação de lixões, associadas à inclusão social e à emancipação econômica de catadores de materiais reutilizáveis e recicláveis;

5 Art. 18. A elaboração de plano municipal de gestão integrada de resíduos sólidos, nos termos previstos por esta Lei, é condição para o Distrito Federal e os Municípios terem acesso a recursos da União, ou por ela controlados, destinados a empreendimentos e serviços relacionados à limpeza urbana e ao manejo de resíduos sólidos, ou para serem beneficiados por incentivos ou financiamentos de entidades federais de crédito ou fomento para tal finalidade.

$\S 1^{\circ}$ Serão priorizados no acesso aos recursos da União referidos no caput os Municípios que:

I - optarem por soluções consorciadas intermunicipais para a gestão dos resíduos sólidos, incluída a elaboração e implementação de plano intermunicipal, ou que se inserirem de forma voluntária nos planos microrregionais de resíduos sólidos referidos no $\S 1^{\circ}$ do art. 16;

II - implantarem a coleta seletiva com a participação de cooperativas ou outras formas de associação de catadores de materiais reutilizáveis e recicláveis formadas por pessoas físicas de baixa renda. 


\section{Responsabilidade Compartilhada}

Essa responsabilidade compartilhada, disposta no Art. 30 da Legislação Nacional, já vinha sendo utilizada em legislações estaduais, tais como a Lei 18.031/09, que dispõe sobre a Política Estadual de Resíduos Sólidos do Estado de Minas Gerais:

Art. 4ㅇ, XXIX: Vem atribuir responsabilidade igual para geradores de resíduos sólidos, pessoas públicas ou privadas, e seus contratados, quando esses geradores vierem a utilizar-se dos serviços de terceiros para execução de qualquer das etapas da gestão, do gerenciamento e do manejo integrados dos resíduos sólidos sob sua responsabilidade.

O que se espera é efetividade nesse processo por meio de políticas públicas como essas. Isso porque, a partir do momento que geradores de resíduos sólidos atuam de modo a minimizar o crescimento em potencial destes, o setor empresarial pode atuar implementando e operacionalizado o seu gerenciamento, e toda a coletividade é quem ganha com isso, por poder continuar vivendo em um meio ambiente ecologicamente equilibrado.

Desta forma, abranger fornecedores no manejo e responsabilidade para com esse passivo gerado, dá credibilidade ao que a Lei 12.305/10 dispõe, considerando que o Código de Defesa do Consumidor (Lei 8078/90), dispõe que:

Art. $3^{\circ}$. Fornecedor é toda pessoa física ou jurídica, pública ou privada, nacional ou estrangeira, bem como os entes despersonalizados, que desenvolvem atividade de produção, montagem, criação, construção, transformação, importação, exportação, distribuição ou comercialização de produtos ou prestação de serviços.

Desta forma, todos os agentes elencados no referido artigo passam a ser responsáveis pela contratação de serviços de coleta, armazenamento, transporte, transbordo tratamento e destinação final dos resíduos sólidos, tornando viável a coleta, bem como cooperando para com os catadores e cooperativas.

Essa responsabilidade compartilhada também proposta pela nova lei, atua no sentido de impor a todos os operadores do mercado, o seu papel pela destinação final dos resíduos:

Art. 31. Sem prejuízo das obrigações estabelecidas no plano de gerenciamento de resíduos sólidos e com vistas a fortalecer a responsabilidade compartilhada e seus objetivos, 
os fabricantes, importadores, distribuidores e comerciantes têm responsabilidade que abrange:

I - investimento no desenvolvimento, na fabricação e na colocação no mercado de produtos:

a) que sejam aptos, após o uso pelo consumidor, à reutilização, à reciclagem ou a outra forma de destinação ambientalmente adequada;

b) cuja fabricação e uso gerem a menor quantidade de resíduos sólidos possível;

II - divulgação de informações relativas às formas de evitar, reciclar e eliminar os resíduos sólidos associados a seus respectivos produtos;

III - recolhimento dos produtos e dos resíduos remanescentes após o uso, assim como sua subseqüente destinação final ambientalmente adequada, no caso de produtos objeto de sistema de logística reversa na forma do art. 33;

IV - compromisso de, quando firmados acordos ou termos de compromisso com o Município, participar das ações previstas no plano municipal de gestão integrada de resíduos sólidos, no caso de produtos ainda não inclusos no sistema de logística reversa.

Para produtos como agrotóxicos, pilhas e baterias, pneus, óleo lubrificantes, lâmpadas fluorescentes e resíduos eletroeletrônicos, há uma política um pouco diferenciada, ou seja, nesses casos é obrigatória a estruturação e implementação da logística reversa, que "é o conjunto de ações e procedimentos destinados a facilitar a coleta e a restituição dos resíduos sólidos aos geradores, para que sejam tratados ou reaproveitados em seu próprio ciclo produtivo ou no ciclo produtivo de outros produtos.

Isso porque, para esses tipos de resíduos, fica inviável a reciclagem por meio das cooperativas, precisando assim de um trabalho mais aprofundado para realização da reciclagem, exemplo disso é o caso do resíduo eletrônico, para o qual vem sendo montadas verdadeiras "garimpagens" para coleta de metais pesados existentes em tais resíduos.

O Conselho Nacional do Meio Ambiente, por meio da Resolução do № 401/2008, Art. 3ำ, § 3ㅇ, já apresentava disposição para os resíduos de pilhas e baterias:

Art. 3․ Os fabricantes nacionais e os importadores de pilhas e baterias referidas no Art. 1으 e dos produtos que as contenham deverão: [...] 
$\S 30$ [...] considerar que as pilhas e baterias a serem recebidas ou coletadas sejam acondicionadas adequadamente e armazenadas de forma segregada, até a destinação ambientalmente adequada, obedecidas às normas ambientais e de saúde pública pertinentes, contemplando a sistemática de recolhimento regional e local.

Embora haja legislação ou políticas públicas para essa destinação, o que ocorre, na maioria das vezes, é que elas não são implementadas na prática.

Dessa forma, o que se pretende é fazer com que fabricantes, importadores, distribuidores e comerciantes destes produtos estruturem locais de coleta destes resíduos de forma a implementar a logística reversa dos mesmos, fazendo com que o produto usado volte para os consumidores depois de reprocessados.

Nesse ponto, a coleta é muito importante, desde que feita de forma segregada para estes tipos de resíduos. Isso porque, fica mais rápido o seu retorno para os fabricantes quando coletados ainda limpos, aptos a serem levados ao processo de logística reversa.

Essas ações por parte do setor empresarial trazem materialidade ao que a nova legislação propõe e demonstram sua responsabilidade perante a sociedade.

A gestão compartilhada pelo ciclo de vida dos produtos, no que se refere à atuação do titular dos serviços públicos de limpeza urbana e manejo de resíduos sólidos, observado, se houver o plano municipal de gestão integrada de resíduos sólidos, Art. 36, determina a ele a implantação de cooperativas de catadores, conforme disposto no $§ 1$ 10:

$\S 1^{\circ}$. Para o cumprimento do disposto nos incisos I a IV do caput, o titular dos serviços públicos de limpeza urbana e de manejo de resíduos sólidos priorizará a organização e o funcionamento de cooperativas ou de outras formas de associação de catadores de materiais reutilizáveis e recicláveis formadas por pessoas físicas de baixa renda, bem como sua contratação.

A coletividade, por sua vez, cabe o papel principal da separação dos materiais recicláveis para a coleta seletiva, acondicionando adequadamente e disponibilizando os resíduos para que os mesmos possam ser reaproveitados. Essa é uma condição mínima para o sucesso da logística sustentável. 
Isso só faz demonstrar a preocupação constante do Poder Público, dos geradores e da coletividade para o problema com o meio ambiente, que só tende a piorar se essas ações não forem postas em prática de forma efetiva por todos.

Este é o verdadeiro teor da responsabilidade compartilhada, ora proposta e que deve fazer parte do Plano Municipal de Gestão Integrada de Resíduos Sólidos, proposto pela nova Lei de Resíduos Sólidos.

\section{Dinâmica da logística reversa}

Para viabilizar tecnicamente o meio ambiente sustentável, o setor empresarial vem desenvolvendo a logística reversa do resíduo gerado, com a comercialização de seus produtos.

A logística reversa é um gerenciamento da cadeia de suprimentos. É um sistema de logística resultante do consequente atendimento e da alta rotatividade do mercado globalizado.

Dessa forma, devido à descartabilidade dos produtos em geral, bem como do avanço em exponencial da tecnologia, a qual acelera a obsolescência dos produtos, o gerenciamento da cadeia de suprimentos de forma reversa passa a ter viabilidade técnica ambiental.

Em obra específica sobre logística reversa, Leite (2003, p. 26) expõe o seguinte:

Com o aumento do descarte dos produtos de utilidade após seu primeiro uso, há um desequilíbrio entre as quantidades de resíduos descartados e as reaproveitadas, tornando o lixo urbano um dos mais graves problemas ambientais da atualidade.

O autor ainda acrescenta, (2003, p. 27):

A logística reversa é a área da logística empresarial que planeja, opera e controla o fluxo e as informações logísticas correspondentes, do retorno dos bens de pósvenda e de pós-consumo ao ciclo dos negócios ou ao ciclo produtivo, por meio dos canais de distribuição reversa, agregando-lhes valor de diversas naturezas: econômico, ecológico, legal, logístico, de imagem corporativa, entre outros. 
Essa é a aposta no consumo consciente, que fez a lei de resíduos sólidos, em seu Art. 33, dentre outras implementações, dispor sobre a obrigação de estruturar e implementar sistemas de logística reversa:

Art. 33. São obrigados a estruturar e implementar sistemas de logística reversa, mediante retorno dos produtos após o uso pelo consumidor, de forma independente do serviço público de limpeza urbana e de manejo dos resíduos sólidos, os fabricantes, importadores, distribuidores e comerciantes de:

1 - agrotóxicos, seus resíduos e embalagens, assim como outros produtos cuja embalagem, após o uso, constitua resíduo perigoso, observadas as regras de gerenciamento de resíduos perigosos previstas em lei ou regulamento, em normas estabelecidas pelos órgãos do Sisnama, do SNVS e do Suasa, ou em normas técnicas;

II - pilhas e baterias;

III - pneus;

IV - óleos lubrificantes, seus resíduos e embalagens;

V - lâmpadas fluorescentes, de vapor de sódio e mercúrio e de luz mista;

$\mathrm{VI}$ - produtos eletroeletrônicos e seus componentes.

O Art. 33으, § 3 ainda assevera que devem ser tomadas medidas para assegurar a implementação e operacionalização da logística reversa, por parte de fabricantes, importadores, distribuidores e comerciantes:

$\S$ 3. Sem prejuízo de exigências específicas fixadas em lei ou regulamento, em normas estabelecidas pelos órgãos do Sisnama e do SNVS, ou em acordos setoriais e termos de compromisso firmados entre o poder público e o setor empresarial, cabe aos fabricantes, importadores, distribuidores e comerciantes dos produtos a que se referem os incisos II, III, V e VI ou dos produtos e embalagens a que se referem os incisos I e IV do caput e o $\S$ 10 tomar todas as medidas necessárias para assegurar a implementação e operacionalização do sistema de logística reversa sob seu encargo, consoante o estabelecido neste artigo, podendo, entre outras medidas:

I - implantar procedimentos de compra de produtos ou embalagens usados;

II - disponibilizar postos de entrega de resíduos reutilizáveis e recicláveis; 
III - atuar em parceria com cooperativas ou outras formas de associação de catadores de materiais reutilizáveis e recicláveis.

Esse princípio da cooperação, segundo Leite e Ayala (2010, p. 55-56), "necessita, para a sua consecução, do exercício da cidadania participativa e, mais que isso, da cogestão dos diversos Estados na preservação da qualidade ambiental". Mateo (1995, p. 44) ainda elenca que "a cooperação visa a uma gestão do patrimônio ambiental comum".

Partindo-se desses princípios, espera-se que a logística reversa comece no momento em que o produto é produzido, se estendendo ao ato da compra e reiniciando o ciclo quando é devolvido como matéria prima para ser reprocessado.

Além disso, o que deve ser levado em conta é que esse processo também deve gerar viabilidade técnica e econômica. Montar uma estrutura dessas exige uma injeção de recurso, é nesse sentido que a lei dos resíduos assim elenca:

Art. 42. O poder público poderá instituir medidas indutoras e linhas de financiamento para atender, prioritariamente, às iniciativas de:

I - prevenção e redução da geração de resíduos sólidos no processo produtivo;

II - desenvolvimento de produtos com menores impactos à saúde humana e à qualidade ambiental em seu ciclo de vida;

III - implantação de infra-estrutura física e aquisição de equipamentos para cooperativas ou outras formas de associação de catadores de materiais reutilizáveis e recicláveis formadas por pessoas físicas de baixa renda;

E ainda, mais especificadamente com relação às cooperativas de catadores, tratando de incentivos para tanto, assim expõe:

Art. 44. A União, os Estados, o Distrito Federal e os Municípios, no âmbito de suas competências, poderão instituir normas com o objetivo de conceder incentivos fiscais, financeiros ou creditícios, respeitadas as limitações da Lei Complementar $n^{\circ} 101$, de 4 de maio de 2000 (Lei de Responsabilidade Fiscal), a:

I - indústrias e entidades dedicadas à reutilização, ao tratamento e à reciclagem de resíduos sólidos produzidos no território nacional; 
II - projetos relacionados à responsabilidade pelo ciclo de vida dos produtos, prioritariamente em parceria com cooperativas ou outras formas de associação de catadores de materiais reutilizáveis e recicláveis formadas por pessoas físicas de baixa renda;

Assim, é neste sentido que a temática ora apontada com certeza trará mais inclusão a esses catadores, que de certa forma, participam do processo de reciclagem dos resíduos. Esses catadores participam em um momento chave do processo, por isso é que medidas sujeitas a facilitar e a dar efetividade econômica a estes devem ser colocadas em pratica pelo Poder Público, setor empresarial e pela sociedade.

Na opinião Derani (1999, p. 100), diante da questão econômica, tece a autora o seguinte apontamento:

\begin{abstract}
A realização do direito ao meio ambiente ecologicamente equilibrado pressupõe a obediência ao princípio da defesa do meio ambiente nas atividades econômicas. Sendo um direito fundamental a ser construído na atividade social, somente a atividade social - por conseguinte a atividade econômica- que contemple o princípio da defesa do meio ambiente poderá concretizá-lo. Assim, será conforme o direito aquela atividade que no seu desenvolvimento orienta-se na defesa do meio ambiente e, deste modo, contribui na concretização do direito fundamental social ao meio ambiente ecologicamente equilibrado.
\end{abstract}

Assim, tem-se que essa concretização do direito fundamental para um meio ambiente ecologicamente equilibrado, tem por meio da gestão da logística reversa do resíduo, proposta pela Política Nacional de Resíduos Sólidos, uma forma de gerenciar e operacionalizar o retorno de bens e materiais, agregando valor ao mesmo, procurando a preservação desse meio ambiente ecologicamente equilibrado, o qual, segundo Silva (2000, p. 20), "é a interação do conjunto de elementos naturais, artificiais e culturais que propiciem o desenvolvimento equilibrado da vida em todas as suas formas". Por isso é que vem a ser condição sine qua non ser "equilibrado".

Essa preocupação ambiental deve ser um diferencial competitivo, fomentado por meio de objetivos econômicos. Só assim, em um mercado globalizado, é que se poderá estruturar e implementar a logística reversa, conforme dispõe o Art. 33 da nova lei. 


\title{
5 As cooperativas de catadores
}

A operacionalização da responsabilidade compartilhada, bem como da logística reversa, propostos pela nova legislação do resíduo sólido, só terão seguimento se a organização de cooperativas e associações de reciclagem forem estimuladas pelo Poder Público, principalmente, inclusive com incentivos e recursos financeiros que facilitem sua consolidação como instrumentos indispensáveis na gestão dos resíduos sólidos.

A Agenda 21, que é um valioso documento entregue a nação em 2002, já em seu bojo propõe estratégias a serem executadas para programar a eficácia e velocidade da proteção ambiental por meio da inserção à sociedade daqueles que participam do processo, como traz Milaré (2007, p. 93):

\begin{abstract}
A agenda 21 brasileira é uma proposta realista e exeqüível de desenvolvimento sustentável, desde que se levem em consideração as restrições econômicas, político-institucionais e culturais que limitam sua implementação. Para que essas propostas estratégicas possam ser executadas com maior eficácia e velocidade será indispensável que: o nível de consciência ambiental e de educação para a sustentabilidade avance; o conjunto do empresariado se posicione de forma pró ativa quanto às suas responsabilidades sociais e ambientais; a sociedade seja mais participativa e que tome maior número de iniciativas próprias em favor da sustentabilidade; a estrutura do sistema político nacional apresente maior grau de abertura para as políticas de redução das desigualdades e de eliminação da pobreza absoluta.
\end{abstract}

Partindo desse planejamento, proposto pela Agenda 21, a idéia é que as empresas tenham organizações de trabalhadores em reciclagem, bem como parcerias estratégicas em suas responsabilidades de acompanhamento e retorno de seus produtos, sendo indispensáveis atividades técnicas e operacionais comuns, fechando o ciclo da reciclagem do produto.

Espera-se que os acordos setoriais entre poderes públicos e setores empresariais possam garantir a capacitação de trabalhadores internos e externos às empresas, possibilitando a formação de mão de obra qualificada. O aumento da demanda possibilitará novas atividades econômicas, gerando trabalho e renda de qualidade para um contingente importante da sociedade. 
Para que essa atividade econômica se torne viável, há iniciativas fomentadoras como os chamados impostos verdes, o qual segundo Ribas, $(2005$, p. 686) é assim conceituado:

Previsão constitucional para tributação diferenciada sobre produtos essenciais, pela seletividade de alíquota. Neste sentido, e tendo em vista as orientações dos arts. $170, \mathrm{VI}$ e 225 , pode o legislador, em caráter extrafiscal, desestimular as atividades inconvenientes ao bem-estar social. A majoração de alíquotas incidentes sobre produtos ecologicamente incorretos permite a transferência dos custos sociais provocados pelo dano para as indústrias poluentes.

A emancipação econômica dos catadores de materiais recicláveis e reutilizáveis é uma das metas mínimas no processo de eliminação dos lixões e recuperação das áreas degradadas por depósitos inadequados, estabelecidas nos planos nacional, estaduais, intermunicipais e municipais de gestão integrada dos resíduos sólidos, como já tratado anteriormente, além de ser meta da nova legislação.

A organização e inserção destes trabalhadores na economia formal irão dinamizar as economias locais e regionais possibilitando à inclusão de trabalhadores que são atualmente marginalizados e distantes da segurança social e da cidadania plena, dando assim efetividade à política proposta.

Os poderes públicos, empresas e sociedade são indispensáveis para fortalecer os processos de inclusão social, estimulando as organizações de trabalhadores, facilitando as relações entre estes e os órgãos públicos ou empresas, separando e classificando seus resíduos e possibilitando que o país possa ter um futuro sustentável, com organização e inclusão social que garanta o fortalecimento do povo, especialmente os mais pobres e excluídos dos benefícios do consumo de cada dia.

Com a introdução da responsabilidade compartilhada, envolvendo sociedade, empresas, prefeituras e governos estadual e federal na gestão dos resíduos sólidos, isso afetará profundamente nas cooperativas isso porque, as pessoas terão de acondicionar de forma adequada o lixo para o recolhimento do mesmo, fazendo a separação onde houver a coleta seletiva.

Já a partir da sistemática da logística reversa, onde fabricantes, importadores, distribuidores e vendedores realizaram o recolhimento de embalagens usadas, como visto 
anteriormente, isso fará com que as cooperativas tenham um incentivo ainda maior para o seu funcionamento, bem como para geração de lucro rápido.

Assim, uma pergunta paira no ar: O que vai melhorar para o meio ambiente e para a geração de renda das pessoas?

Considerando que a maior parte dos resíduos produzidos no Brasil é encaminhada para lixões sem nenhum controle sanitário, inclusive dos riscos para as populações que sobrevivem da reciclagem e nos arredores destas áreas, uma política que objetiva erradicar os lixões e que tem como diretriz a não geração, redução, reutilização, reciclagem e tratamento adequado dos resíduos sólidos e a disposição final ambientalmente correta dos rejeitos será uma contribuição importante para garantir a qualidade de vida das futuras gerações.

Desta forma, a geração de emprego para esta população que já vivia à margem da sociedade, incluindo a mesma no eixo econômico do país, fará com que tudo se volte para o objetivo pretendido, ou seja, preservação do meio ambiente.

Em relação à geração de trabalho e renda, a responsabilidade compartilhada e a logística reversa, conforme já explicitado anteriormente, bem como os planos integrados dos poderes públicos e os planos de gerenciamento das empresas contribuirão para a organização dessas cooperativas e associações de reciclagem.

Conclui-se, portanto, que a emancipação econômica e a organização destes trabalhadores precisa ser uma das metas dos planos de gerenciamento dos resíduos sólidos, que deve ser elaborado através da mobilização social e da realização de consultas e audiências públicas.

\section{Meio Ambiente e sociedade de risco}

O Meio Ambiente atual está passando por diversas intempéries ocasionadas pela ganância humana. Daí a se designa-la como sociedade de risco.

O surgimento da sociedade de risco, segundo Beck e Giddens (1997, p. 135), "designa um estágio da modernidade no qual começam a tomar corpo ameaças produzidas até então pelo modelo econômico da sociedade." Segundo Leite (2004, p. 131), "a sociedade 
de risco representa a tomada de consciência do esgotamento do modelo de produção, sendo esta marcada pelo risco permanente de desastres e catástrofes.".

A sociedade de risco é aquela que, em razão do contínuo crescimento da sociedade é possível prever conseqüências de uma catástrofe ambiental a qualquer tempo. Isto porque não existe uma adequada e eficiente relação econômica e jurídica que passa adequadamente dar solução aos problemas gerados pela sociedade de massa. Para isso, necessário se faz proteger a sociedade tida como sustentável.

Para Souza (2007, p. 267-268) tem-se que:

Para viabilizar a sociedade sustentável, é imperativo uma nova postura, tanto dos agentes econômicos, que devem passar a incorporar as chamadas externalidades, quanto dos juristas, que devem criar um conjunto de regras adequadas para tornar efetivas as proposições emanadas das áreas técnicas.

Para Leite, (2004, p. 128-129) com relação à temática estudada tem-se o seguinte apontamento:

O problema suscitado ao Direito Ambiental na sociedade de risco não é, portanto, exatamente apensos ao de compreensão inadequada da nova ordem de problemas que se estabelecem a partir de composições e relações, mas o de tomar decisões a partir da qualidade diferenciada desses problemas, o que importa em considerar, sinteticamente, o problema de como superar da melhor forma possível o conjunto de imprevisões, incertezas e indefinições que tipificam os processos em que decisões e escolhas devem ser realizadas para a concretização dos objetivos de proteção do ambiente nas sociedades de risco.

Em uma visão ampla, deve se reconhecer que a gestão dos riscos não pode dado ao anonimato, à invisibilidade, à acumulação, à indeterminação temporal e espacial, ser convenientemente controlado, e, sobretudo, regulado a partir do grau de conhecimento técnico-especializado disponível no momento de seu desenvolvimento. Agora, o seu passivo, perante o Meio Ambiente, representa um vínculo com o futuro que tenciona a uma responsabilidade mais poderosa, esperando a partir daí uma proposta cidadã de participação. Assim, segundo Leite (2004, p. 131), "da realização desse atributo depende um modelo de cidadania efetivamente adequado, funcional e compatível com a proposta de gestão dos riscos.". 
A recém promulgada Lei de Política Nacional de Resíduos Sólidos, já abordada anteriormente, além de evidenciar a importância para com a coleta seletiva e as cooperativas de catadores, evidencia ainda a necessidade de cuidados, como por exemplo, ao tratar dos princípios em seu Art. $6^{\circ}$, destacando-se entre eles o da precaução, prevenção, desenvolvimento sustentável, evidenciando ainda a necessária responsabilização compartilhada para com ciclo de vida do produto e o destino dos resíduos.

No entanto, há problemas que o Estado se revela, e efetivamente é incapaz de resolver. Entre eles se destaca a gestão dos resíduos sólidos urbanos onde o principal instrumento é a coleta seletiva que só terá êxito nas comunidades onde houver organização da sociedade civil e vontade política do Poder Público na solução do problema.

Na definição desses contornos, parte-se da premissa que informação e democracia ambiental organizada podem vir a objetivar condições de um futuro possível, por isso que para dizimar essa sociedade de risco que norteia a todos, só será possível se para aqueles que participam efetivamente da logística do resíduo seja inserido na sociedade e reconhecido.

A inclusão social destes trabalhadores é princípio fundamental para a preservação do meio ambiente, trazendo para a sociedade a transformação do resíduo, de certa forma.

\section{Responsabilidade Ambiental}

Sendo a responsabilidade ambiental gerida pelos Princípios Fundamentais do Direito Ambiental, como o princípio da prevenção e o princípio da precaução, manter o meio ambiente ecologicamente equilibrado é responsabilidade de todos.

Leite e Ayala (2010, p. 112) ao tratar da responsabilidade ambiental, diz que esta "tem o sentido de demonstrar ao público que a racionalidade jurídica nas esferas do ambiente ultrapassa um olhar técnico, dogmático e monodisciplinar."

Sendo os recursos naturais esgotáveis, necessário se faz uma gestão integrada de responsabilização dos resíduos lançados na natureza, uma vez que, na grande maioria, são rejeitados de forma indiscriminada no solo e na água. 
Nesse sentido, Ayala (2003, p. 63), ao tratar da temática numa visão voltado para as presentes e futuras gerações, tem o seguinte posicionamento quanto a responsabilidade ambiental:

\begin{abstract}
A possibilidade de um futuro não é promessa, mas compromisso, que só pode ser realizado mediante uma tríade de condições estruturadas em torno da participação da informação e da repartição de responsabilidade (solidariedade). O possível deixa desta forma, de ser socialmente reproduzido como expressão que identifica condições de imobilismo ou de impotência perante um futuro inacessível, desconhecido, e incompreensível, para a qualidade de objetivo de compromisso jurídico tendente à conscientização, tarefa que dependem de severos compromissos de solidariedade.
\end{abstract}

Abaixo, segue uma linha do tempo, onde o foco é justamente o crescimento do conceito de responsabilidade social e responsabilidade ambiental:

1929- Constituição de Weimar (Alemanha) - Função Social da Propriedade;

1960- Movimentos pela Responsabilidade Social (EUA);

1971- Encontro de Founex (Suíça)

1972- Singer publica o que foi reconhecido como o primeiro balanço social do mundo;

1972- ONU - resolução 1721 do Conselho Econômico e Social - estudos sobre o papel das grandes empresas nas relações internacionais;

1973- PNUMA Programa das Nações Unidas para o Meio Ambiente (Genebra)

1977- determinação da publicação do balanço social - relações do trabalho (França);

1992- ECO 92 ou CNUMAD (Conferencia das Nações Unidas para o Meio Ambiente e o Desenvolvimento) - Criação do Projeto Agenda 21;

1997- Betinho de Souza e IBASE incentivam publicação do balanço social;

1999- Criação do Selo "Empresa Cidadã";

1999- 1a Conferência Internacional do Instituto Ethos;

2000- ONU e o Pacto Global;

Fonte: www.ethos.com.br 
Isso mostra o quanto já se inovou no assunto da preservação ambiental e que é real a preocupação em se fechar o ciclo para finalmente chegar a balanços positivos com relação à reciclagem de resíduos, bem como incluir neste processo dignidade aos catadores, e cooperativas.

Na Lei $12.305 / 10$, é clara a participação do poder público nas fases desse processo, inclusive quanto trata da responsabilidade solidária, art. 25으, a responsabilidade subsidiária, Art. 29으 e responsabilidade compartilhada no Art. 30 ㅇ․

Art. 25․ O poder público, o setor empresarial e a coletividade são responsáveis pela efetividade das ações voltadas para assegurar a observância da Política Nacional de Resíduos Sólidos e das diretrizes e demais determinações estabelecidas nesta Lei e em seu regulamento. [...]

Art. 29․ Cabe ao poder público atuar, subsidiariamente, com vistas a minimizar ou cessar o dano, logo que tome conhecimento de evento lesivo ao meio ambiente ou à saúde pública relacionado ao gerenciamento de resíduos sólidos. [..]

Art. 30ㅇ. É instituída a responsabilidade compartilhada pelo ciclo de vida dos produtos, a ser implementada de forma individualizada e encadeada, abrangendo os fabricantes, importadores, distribuidores e comerciantes, os consumidores e os titulares dos serviços públicos de limpeza urbana e de manejo de resíduos sólidos.

Espera-se que, com a Nova Lei, a gestão dos resíduos seja realizada com a responsabilidade e a participação efetiva de todos.

A Política Nacional de Resíduos Sólidos terá papel fundamental na inclusão econômica, social e cultural das pessoas que vivem, convivem e sobrevivem das atividades de reutilização e reciclagem de produtos, materiais e embalagens pós consumo. A responsabilidade e gestão compartilhadas entre fabricantes, importadores, distribuidores, comerciantes, poderes públicos e consumidores terá na logística reversa operacionalizada pelas cooperativas e associações de trabalhadores em reciclagem uma das principais ferramentas de gestão.

As cooperativas também serão parceiras estratégicas dos municípios e consórcios na operacionalização dos programas integrados de resíduos sólidos em suas áreas de atuação. 


\section{Considerações Finais}

Pelo exposto, tem-se que a operacionalização da nova legislação sobre resíduos sólidos no âmbito da inclusão social dos catadores, bem como das cooperativas de catadores só terá eficácia se Poder Público, setor empresarial e toda a sociedade trabalharem em conjunto para o fecho deste ciclo da reciclagem.

Assim, por meio da responsabilidade compartilhada de todos estes, espera-se que os catadores, agentes fundamentais para o processo de coleta dos resíduos, possam ter uma vida digna, perante a função tão merecedora desta atividade que desempenham.

Tudo isso proporcionará a estes independência econômica acima de tudo, o que por certo fomentará a economia. Assim, trazendo a estes agentes, que sempre viveram a margem da sociedade, para o meio do ciclo da reciclagem, reconhecendo seu verdadeiro valor, com certeza o objeto principal de todo o sistema, ou seja, a preservação do meio ambiente, será mais eficaz.

A coleta e reciclagem dos resíduos, por parte dos catadores, faz com que estes não sejam depositados indiscriminadamente no meio ambiente, preservando-o para as presentes e futuras gerações.

A nova política dos resíduos, por meio da responsabilidade compartilhada, da logística reversa dos resíduos, da efetividade dos princípios e principalmente da participação do Poder Púbico para com a operacionalidade das cooperativas de catadores, trará conseqüências importantes para toda a sociedade. Por isso, mister o papel de todos neste ciclo de inclusão destes agentes importantes para a transformação da sociedade de risco, diminuindo gradativamente o risco ambiental.

\section{Referências}

ABNT - Associação Brasileira de Normas Técnicas. NBR 12235:1992: armazenamento de resíduos sólidos perigosos. Rio de Janeiro: ABNT, 1992.

. NBR 10004:2004: resíduos sólidos. 2. ed. Rio de Janeiro: ABNT, 2004.

AYALA, Patrick de Araújo. A proteção jurídica das futuras gerações na sociedade do risco global: direito ao futuro na ordem constitucional brasileira. In: LEITE, José Rubens Morato; BELTRÃO, Antonio F. G. Curso de direito ambiental. Rio de Janeiro: Forense, 2009. 38 
BRASIL. Lei № 8.078, de 11 de setembro de 1990, dispõe sobre a proteção do consumidor e dá outras providências. 1990. Disponível em <http//:www.planalto.gov.br>. Acesso em: mar. 2011.

. Lei № 4191, de 30 de setembro de 2003, dispõe sobre a política estadual de resíduos sólidos e dá outras providências. 2003. Disponível em <http//:www.planalto.gov.br>. Acesso em: mar. 2011.

. Lei № 12.305, de 2 de agosto de 2010, institui a Política Nacional de Resíduos Sólidos. 2010. Disponível em: <www.república.gov.br>. Disponível em $<$ http//:www.planalto.gov.br>. Acesso em: mar. 2011.

CONAMA - Conselho Nacional do Meio Ambiente. Resolução № 401, de 4 de novembro de 2008, estabelece os limites máximos de chumbo, cádmio e mercúrio para pilhas e baterias comercializadas no território nacional e os critérios e padrões para o seu gerenciamento ambientalmente adequado, e dá outras providências. 2008.

DE PLÁCIDO E. SILVA, Vocabulário jurídico. 27 ed. Rio de Janeiro: Forense, 2007.

DERANI, Cristiane. Meio ambiente ecologicamente equilibrado: direito fundamenta e princípio da atividade econômica. In: FIQUEIREDO, Guilherme Jose Purvin de (org.). Temas de direito ambiental e urbanístico. São Paulo: Max Limond, 1999.

LEITE, Paulo Roberto. Logística reversa: meio ambiente e competitividade. São Paulo: Prentice Hall, 2003.

LEITE, José Rubens Morato; AYALA, Patryck de Araújo. Direito ambiental na sociedade de risco. Rio de Janeiro: Forense, 2010.

Dano ambiental: do individual ao coletivo extrapatrimonial. São Paulo: Revista dos Tribunais, 2010.

LEITE, José Rubens Morato; BELTRÃO, Antonio F. G. Curso de direito ambiental. Rio de Janeiro: Forense, 2009.

MACHADO, Paulo Affonso Leme. Direito ambiental brasileiro. 18. ed. rev. e atual. São Paulo: Malheiros, 2010.

MATEO, Ramón Martín. Tratado de derecho ambiental. Trivium: Madrid, 1995. 
MILARÉ, Édis. Direito do ambiente: doutrina, prática, jurisprudência, glossário. São Paulo: Revista dos Tribunais, 2005.

MILARÉ, Édis. Direito do ambiente: doutrina, prática, jurisprudência, glossário. São Paulo: Revista dos Tribunais, 2007.

MINAS GERAIS. Lei № 18.031/2009, dispõe sobre a Política Estadual de Resíduos Sólidos do Estado de Minas Gerais. 2009. Disponível em <http//:www.planalto.gov.br>. Acesso em: out.2010.

RESOLUÇÃO № 401/2008.

RIBAS, Lídia Maria Lopes Rodrigues. Questões de Direito Tributário ambiental em debate: In: TÔRRES Heleno Taveira (Org.). Direito tributário ambiental. São Paulo: Malheiros, 2005

SILVA, José Afonso da. Direito ambiental constitucional. São Paulo: Malheiros, 2000.

Artigo recebido em 15/03/2012 e aprovado para publicação em 06/08/2012. 